\title{
In Vitro Inhibitory Assay of an Isolated Indoor Airborne Fungus from an Institutional Building of Computer Education by Using Potassium Sorbate
}

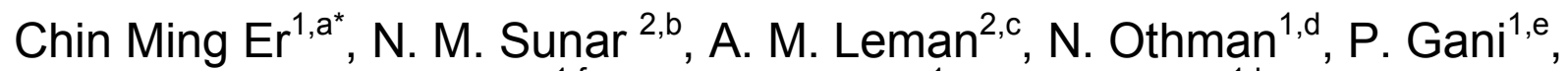 \\ N. A. Jamal ${ }^{1, f}$, Q. A. Emparan ${ }^{1, g}$, U. K. Parjo ${ }^{1, h}$ \\ ${ }^{1}$ Department of Water And Environmental Engineering, Faculty of Civil And Environmental \\ Engineering, University Tun Hussein Onn Malaysia, 86400 Parit Raja, Batu Pahat, Johor, Malaysia \\ ${ }^{2}$ Department of Chemical Engineering Technology, Faculty of Engineering Technology, Universiti \\ Tun Hussein Onn Malaysia, 86400, Parit Raja, Batu Pahat, Johor, Malaysia \\ agf120113@siswa.uthm.edu.my, bshuhaila@uthm.edu.my, cmutalib@uthm.edu.my, \\ dnorzila@uthm.edu.my, ${ }^{\mathrm{d}}$ parancgat@yahoo.com, ${ }^{\mathrm{f}}$ df090252@siswa.uthm.edu.my, \\ gquinston89@gmail.com, humi5506@yahoo.com
}

Keywords: mold colonization, biocide, remediation

\begin{abstract}
Currently, one of the main aspects of health and safety concern to facility owners and supervisors is indoor air quality. Meanwhile, pollution by airborne fungi in these facilities are acquiring more and more consideration due to its possible harmful side effects such as threats to occupiers' health and damage to building parts and furniture. One of the recommendations to solve these indoor fungi pollution is bioactive compound which can act as a biocide. However, assessment of this compound in the real environment is often time-consuming and impractical. In this study, a bioactive compound, potassium sorbate which is commonly applied in food manufacturing was assessed for its efficiency as a biocide to restrict the growth of an isolated airborne fungus using an in vitro inhibition assay. The fungus was isolated from a new building of tertiary education of computer studies. It was grown on both biocide-incorporated MEA and untreated MEA. The diameter of the fungal colonies was noted time to time. The diameter of the colony of the treated fungus was downsized by $41.25 \%$ averagely in comparison with the untreated fungus. It was shown that potassium sorbate can restrict the growth rate of the isolated airborne fungus.
\end{abstract}

\section{Introduction}

The quality of the air in a facility often affects the state of wellness of the people in that enclosed facility [1]. It is termed as indoor air quality (IAQ). IAQ of a facility is known to be important in determining occupants' satisfaction, comfort, and productivity. This is because indoor setting is closest to human beings in terms of day-to-day communication and activities as a large portion of human's daily life is spent here. Nevertheless, there are a lot of places on our Mother Earth, such as our dwellings, schools, colleges and dorms are seriously polluted by airborne fungi. As heterotrophic organisms, fungi easily inhabit on and within organic building materials that can be digested to become their energy sources, such as wallpapers and paint coatings [2]. Fungal pollution in a building has been linked to a lot of health problems such as headache, breathing problems, fungal infection, skin irritation and many others [3]. Indoor occupants' healthiness can also be affected by indoor fungal growth due to the ability of fungi to release poisonous mycotoxins, allergens or spores. Mold spores travel in the indoor air and alight on surfaces of water-damaged or wet building materials to establish new colonies for reproduction. The microscopic size of these released spores allows them to infiltrate deep into the human's breathing system and may reproduce there to cause a variety of illnesses eventually [2]. Youngsters, senior citizens and immunocompromised people are at bigger dangers [4].

High temperature and high relative humidity are among the indoor environmental factors that contribute to the higher occurrence of indoor fungi [5]. Excess dampness is always the reason for 
indoor mold or fungi proliferation. The moist air can be condensed by the high dampness and warm climate on cool surfaces of interior building parts. As a result, this phenomenon gives rise to the indoor mold problems. Proliferation of fungi occurs easily in a building over an extensive temperature range as long as there are adequate humidity and nutrients [5]. Temperature between $15^{\circ} \mathrm{C}$ and $30^{\circ} \mathrm{C}$ is the comfortable zone for most of the fungi [5]. On the other hand, the rest of the fungi favour temperatures lower than or higher than this range [5]. For example, the temperature range between $35^{\circ} \mathrm{C}$ and $50^{\circ} \mathrm{C}$ is suitable for propagation of thermophiles [5]. This phenomenon has created an inevitable problem of indoor fungal pollution in nations such as Malaysia, Singapore, Indonesia or other nations in ASEAN (Association of Southeast Asian Nations) which possess hot and moist weather all the time. This was proven in our earlier investigation where the proliferation of fungi was detected in the air of a chamber with high relative humidity and a temperature of about $25^{\circ} \mathrm{C}$ at a higher institutional building of computer education following treatments like washing and exchanging of the mold-overwhelmed ceiling panels [6]. This gives us an insight that ordinary treatments cannot provide a durable solution to the air pollution by fungi in buildings.

Indoor mold contamination in a higher institutional building of computer education is dangerous. It is proposed that the utilising of shared computers in an institutional setting create huge opportunity for the spread of dangerous fungal pathogens [7]. This is because of the using and touching of computers and its accessories which are not regularly disinfected by countless students day-to-day [7]. The situation may become worsen and uncontrollable if the killer pathogens present on these devices and cause an outbreak of deadly infectious disease. Besides, the comfortability, emotion and feeling of the professors, lecturers, tutors, instructors and learners might be influenced by the poor IAQ of the institutional buildings [8]. Indirectly, the educational process will also be affected [8]. Due to perennial hot and damp climate, higher institutional buildings in nations such as countries in ASEAN require an environmental friendly and enduring solution to this kind air pollution in institutional buildings.

Potassium sorbate is a type of salt of sorbic acid. A variety of manufacturing industry has incorporated sorbates to preserve their products such as in food and beverages, cosmetics, medicinal, and tobacco products since the 1940s [9]. Recently, this bioactive compound had been revealed to successfully restrict the proliferation of two species of fungus obtained from an interior wall surface [2]. It is recommended that this bioactive compound can be an environmentally friendly biocide and long-lasting remediation to solve indoor air pollution by fungi. However, to authors' knowledge, potassium sorbate's ability to remediate the air pollution by fungi has not been assessed yet. This might be due to it is time-consuming and impractical to evaluate the effectiveness of this biocide in real environment. Therefore, the purpose of this study is to assess the effectiveness of potassium sorbate to treat an indoor airborne fungus isolated from a higher institutional building of computer education using an in vitro inhibitory assay.

\section{Materials and Methods}

Isolation of Indoor Airborne Fungus. The samplings of the indoor air was carried out with a single-stage air sampler (SKC, USA) in order to isolate an airborne fungus. The indoor air samples were collected from a fungi-affected site of a higher institutional building of computer education in a Johor-based university in Malaysia.

Suspension of Fungal Spores Preparation. A physiological mixture consisting of Polysorbate 20 and sodium chloride was prepared accordingly to Bellotti et al. [2]. The spores of fungus were obtained from the actively growing isolated airborne fungus grown in Malt Extract Agar (MEA) and inoculated into the physiological mixture to become the suspension of fungal spores. A hemocytometer (Hirschmann EM Techcolor, Germany) and technique of serial dilution were used to tune the suspension's concentration to between $0.3 \times 10^{6}$ spores $/ \mathrm{ml}$ and $0.5 \times 10^{6}$ spores $/ \mathrm{ml}[2]$. 
In Vitro Inhibitory Assay. Three tests (Test A, Test B and Test C) were executed to evaluate the efficiency of potassium sorbate concurrently on the same day. A single drop of about $10^{2}$ spores of the prepared suspension of fungal spores were deposited at the middle of the petri dish of each test. The MEA incorporated with potassium sorbate $0.03 \% \mathrm{w} / \mathrm{v}$ was then poured into these petri dishes. The procedure was repeated with two MEA controls that were free of biocide. All the five samples including controls were cultured in a $37^{\circ} \mathrm{C}$ incubator and the diameter of the fungal colonies produced were logged daily over a period of ten days as described by Bellotti et al. with minor modification on the duration of incubation [2].

\section{Results and Discussion}

According to Bellotti et al. [2], efficiency of potassium sorbate was evaluated by an in vitro inhibitory assay of fungal proliferation as the proliferation of a fungus species can be measured by recording diameters of the fungal colonies formed on culture media against duration of incubation (Figure 1).

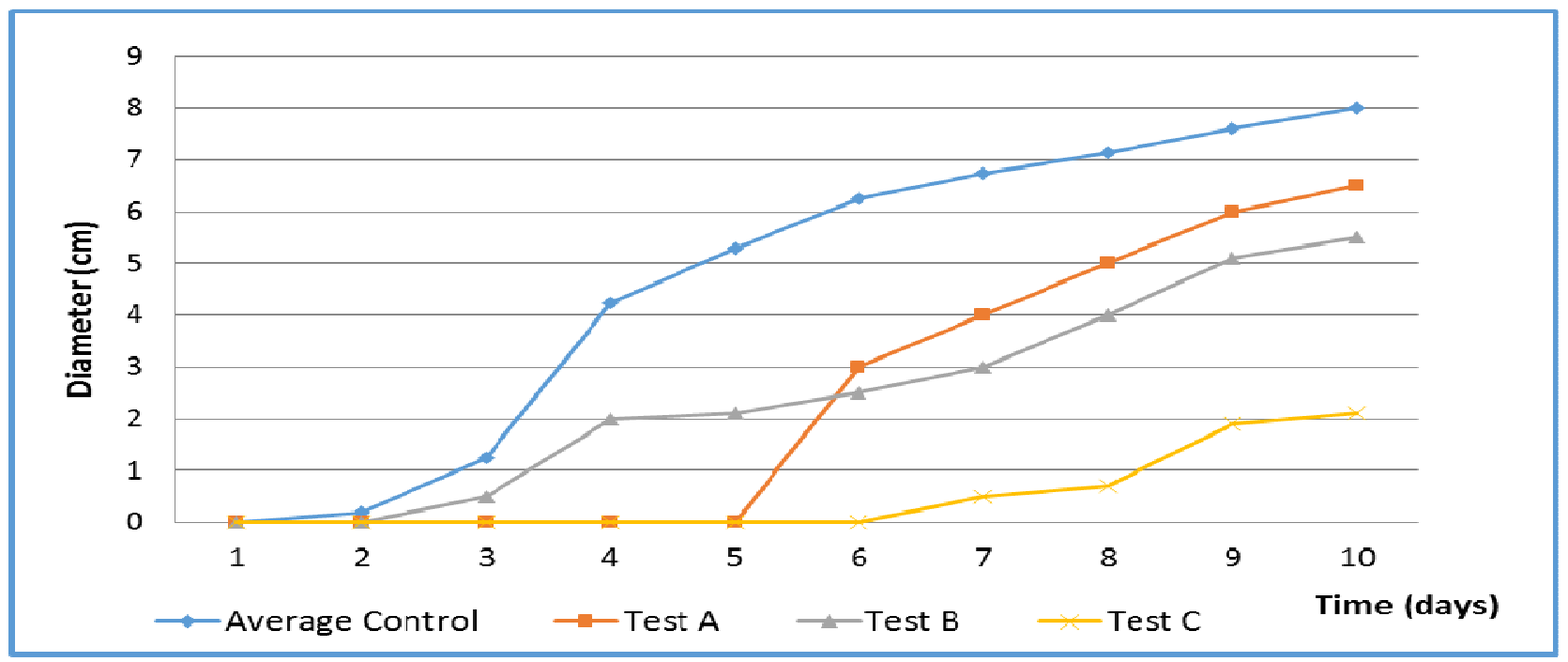

Figure 1: Overall measurement of indoor fungal colony growth diameter during biocide treatment

Potassium sorbate was revealed to be a potent biocide which exhibited high antifungal activity towards the isolated indoor airborne fungus as the colony diameter of the biocide-treated fungus was effectively controlled and reduced. The reduction is $41.25 \%$ on average in contrast to the control samples. There was no growth of the isolated fungus found on the first five days of assay in the biocide-incorporated culture media of Test $\mathrm{A}$ and that of Test $\mathrm{C}$ and slow growth of the fungus was found after that. This shows that the biocide remained highly effective at the early stage of the treatment and its effect was slowly diminishing with time. The results are considered consistent with a 42-week in situ study conducted in Brazil where the fungal colonization on the biocidetreated painted wall surface remained undetected during the initial phase of research till the $31^{\text {st }}$ week, and thereafter, it rose to high levels till the end of the research [10]. Results of this study were possibly due to the slightly acidic nature of potassium sorbate that inhibited the growth of the microbes by penetrating the cytoplasmic membrane of the microbes when dissolved in water [11]. Photographs taken with the biocide-treated and control fungus at the $7^{\text {th }}$ day of incubation are shown in Figure 2.

The fungus growth in Test $\mathrm{C}$ was apparently slower than that in Test $\mathrm{A}$ and Test $\mathrm{B}$. The growth of fungus in Test $\mathrm{C}$ was found only after about a week of incubation. Moreover, the growth after that was found to be extremely slow compared to that of Test A and Test B. Therefore, it is assumed that the inhibitory activity of potassium sorbate can last for a longer time in this test. This 
is possibly owing to the well mixing of biocide and media agar in this test (test $\mathrm{C}$ ) compared to the other two tests.

This study shows that the biocide remains effective against the isolated fungus from the indoor air for at least ten days or longer. Ten days is a good duration for this assay because the colony of the control fungus reached the maximum size of the petri dishes. Further incubation will not show accurate results as the control fungus cannot grow bigger anymore. However, the fungus samples treated by potassium sorbate continued growing slowly by the end of the course of this assay. This is probably due to the biocide in the growing media had depleted.

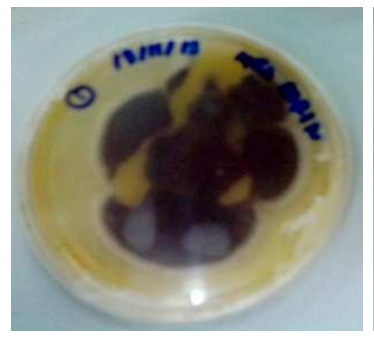

(a) Control 1

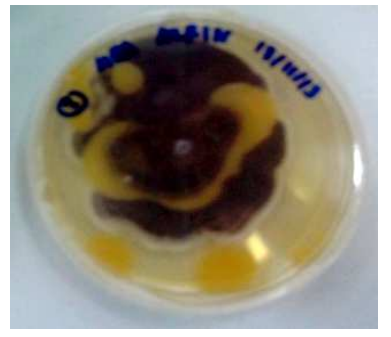

(b) Control 2

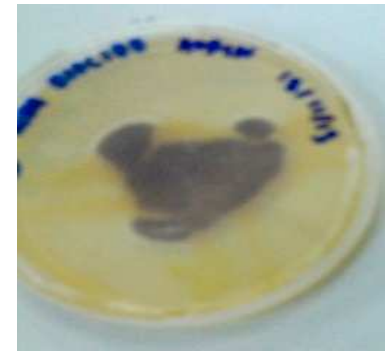

(c) Test A

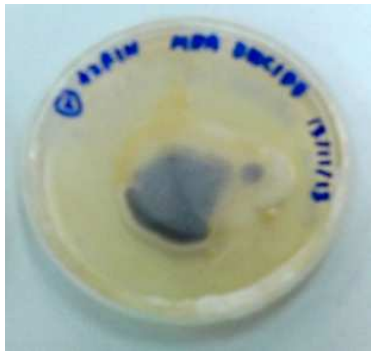

(d) Test B

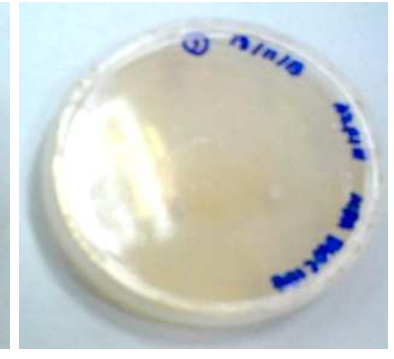

(e) Test C

Figure 2: Untreated fungus (a)-(b) and biocide-treated fungus (c)-(e) after 7 days at $37^{\circ} \mathrm{C}$ incubation.

\section{Conclusion and Recommendation}

It is proven that potassium sorbate gives a good indication to suppress the growth of the isolated indoor airborne fungus. The in vitro inhibitory assay demonstrated in this paper fits to be a low cost and convenience test for preliminary assessment of the effectiveness of a biocide. It is recommended that alternative methods of higher technology such as polymerase chain reaction (PCR) to be sought to test for the durability of this biocide.

\section{Acknowledgement}

The authors acknowledge and thank for the financial assistance from Universiti Tun Hussein Onn Malaysia (UTHM) and Fundamental Research Grant Scheme 1479. 


\section{References}

[1] Yau, Y.H.; Chew, B.T.; and Saifullah, A.Z.A. (2012) Studies on the indoor air quality of Pharmaceutical Laboratories in Malaysia. International Journal of Sustainable Built Environment 1, 110-124.

[2] Bellotti, N., Salvatore, L., Deyá, C., Del Panno, M. T., del Amo, B., \& Romagnoli, R. (2013). The application of bioactive compounds from the food industry to control mold growth in indoor waterborne coatings. Colloids and Surfaces. B, Biointerfaces, 104, 140-4.

[3] Kuhn, D. M., \& Ghannoum, M. A. (2003). Indoor mold, toxigenic fungi, and Stachybotrys chartarum: infectious disease perspective. Clinical microbiology reviews, 16(1), 144-172.

[4] Ayanbimpe, G., Danjuma, W., \& Okolo, M. (2003). Relationship Between Fungal Contamination of Indoor Air and Health Problems of Some Residents in Jos. Cdn.intechopen.com, 1-19.

[5] Dangman, K. H., Schenck, P., DeBernardo, R. L., Yang, C. S., Bracker, A., \& Hodgson, M. J. (2004). Guidance for clinicians on the recognition and management of health effects related to mold exposure and moisture indoors. Farmington, CT: University of Connecticut Health Center, Division of Occupational and Environmental Medicine, Center for Indoor Environments and Health.

[6] Jamal, A. Z. (2014). The remediation of indoor fungal growth isolated from FSKTM by using potassium sorbate as a biocide. Bachelor Degree Thesis. Universiti Tun Hussein Onn Malaysia (UTHM). Malaysia.

[7] Anderson, G., \& Palombo, E. A. (2009). Microbial contamination of computer keyboards in a university setting. American journal of infection control, 37(6), 507-509.

[8] Daisey, J. M., Angell, W. J., \& Apte, M. G. (2003). Indoor air quality ventilation and health symptoms in schools: an analysis of existing information. Indoor Air, 13, 53-64.

[9] Pérez-Prior, M. T., Manso, J. A., García-Santos, M. D. P., Calle, E., \& Casado, J. (2005). Alkylating potential of potassium sorbate. Journal of agricultural and food chemistry, 53(26), 10244-10247.

[10] Shirakawa, M. A., Gaylarde, C. C., Gaylarde, P. M., John, V., \& Gambale, W. (2002). Fungal colonization and succession on newly painted buildings and the effect of biocide. FEMS Microbiology Ecology, 39(2), 165-173.

[11]Pérez, L. M., Balagué, C. E., Rubiolo, A. C., \& Verdini, R. A. (2011). Evaluation of the biocide properties of whey-protein edible films with potassium sorbate to control non-O157 shiga toxinproducing Escherichia coli. Procedia Food Science, 1, 203-209. 